\title{
Neuromotor mechanisms of pharyngoesophageal motility in dysphagic infants with congenital heart disease
}

\author{
Manish B. Malkar ${ }^{1,2}$ and Sudarshan Jadcherla ${ }^{1-3}$
}

\begin{abstract}
BACKGROUND: Aero-digestive morbidities are common in congenital heart disease infants, and the mechanisms are unclear. We hypothesized that adaptive pharyngoesophageal motility reflexes are different in surgical congenital heart disease infants (S-CHD) vs. nonsurgical congenital heart disease infants (CHD) and healthy controls.
\end{abstract}

METHODS: Abrupt pharyngeal provocation was performed with graded water infusions using purpose-built micromanometry. The data from 12 S-CHD were compared with data from 10 CHD and 12 controls. One hundred and ninety-seven water stimulations were examined for the frequency, latency, duration, and magnitude of pharyngo-upper esophageal sphincter contractile response (PUCR), pharyngeal reflexive swallow (PRS), esophageal body peristalsis, and lower esophageal sphincter (LES) relaxation characteristics. Mixed statistical models were applied.

RESULTS: Frequency distribution (\%) of PUCR: PRS: none in S-CHD vs. CHD vs. controls, respectively, were 36:46:17 vs. 9:80:11 vs. 15:61:24 ( $P<0.05)$. Response latency to the final esophageal body waveform $(P=0.01)$ and the response duration of esophageal body peristalsis $(P=0.04)$ were prolonged in S-CHD vs. controls but were similar to $\mathrm{CHD}(P=0.22)$. Pharyngeal infusion-induced LES relaxation characteristics were similar in all three groups.

CONCLUSION: Abnormality in the recruitment of PUCR or PRS reflexes and esophageal body peristalsis in S-CHD implicate dysregulation in vagal cholinergic excitatory neuromotor responses.

c ongenital heart defects are the most common type of birth defects affecting nearly $1 \%$ or $\sim 40,000$ births per year in the United States (1). These infants need parenteral nutrition, innovative enteral feeding strategies, or prolonged respiratory support (2-4). The prevalence of feeding disorders in postsurgical infants with congenital heart disease varies from 22 to $50 \%$ (5-7). Poor nutritional status resulting from inadequate feeding capabilities leads to an imbalance of energy intake resulting in growth failure. Malnutrition is a major problem, which affects the subsequent stages of cardiovascular surgery (8). Furthermore, the acquisition of feeding skills is further delayed among infants with cyanotic congenital heart disease compared with acyanotic congenital heart disease and foregut dysmotility, and oropharyngeal dysphagia neuromotor mechanisms are often implicated but have not been systematically evaluated before (9).

Antecedent conditions for the prototype of the dysphagic infant may include but are not limited to: aero-digestive tract manipulation and surgical trauma in the form of injury to thoracic visceral innervations, postsurgical inflammation, chronic mechanical ventilation, changes in circulation, and influence of anesthesia and narcotics. Furthermore, the risk factors for laryngopharyngeal dysfunction and dysphagia in such infants also include preoperative acuity, duration of intubation, types of congenital heart defect, vocal cord injury, growth characteristics at birth, and the type and duration of surgical procedures (5,6,10-13). Alternatively, feeding difficulties may follow underlying central neurological sequelae or immature brain development $(14,15)$. Regardless of the etiopathological mechanisms for the infant with dysphagia, the final level of functional swallowing coordination and safe regulation occurs at the level of pharyngoesophageal level. These observations form the basis for the current study.

Clarification of the underlying pathophysiological mechanisms of pharyngoesophageal motility reflexes can help us devise better evidence-based management strategies for the prevention and treatment of infant-feeding disorders. In this study, our objective was to test the hypothesis that dysphagic infants with congenital heart disease, who underwent cardiac surgery (S-CHD group), have distinct basal and adaptive pharyngoesophageal motility characteristics compared with that of healthy controls or those infants who did not undergo cardiac surgery (CHD group).

\section{RESULTS}

Demographic and Disease Characteristics

Demographic characteristics are summarized in Table 1. At evaluation, all the 12 control infants had independent oral feeding skills contrasting 12 surgical congenital heart disease infants (S-CHD) and 10 nonsurgical congenital heart disease infants (CHD) who were dysphagic and nasogastric 
tube-dependent. Specific symptom profiles in congenital heart disease infants were: poor oral extraction, $(n=4,18 \%)$; aerodigestive symptoms such as bradycardia, oxygen desaturation, coughing, and arching during swallowing $(n=9 ; 41 \%)$, arching, and irritability $(n=14 ; 64 \%)$; and feeding aversion or behavioral symptoms $(n=2 ; 9 \%)$. Fifty percent of infants in S-CHD group and $40 \%$ of infants in CHD group had gastrostomy tube for feeding at discharge in contrast to none in control group $(P<0.05)$. Tables 2 and 3 provide the details for the individual demographic and disease characteristics of S-CHD and CHD infants, respectively.

\section{Recruitment Frequency of Pharyngo-Upper Esophageal Sphincter Responses to Pharyngeal Stimuli}

Responses to 74,67 , and 56 pharyngeal water stimulations were analyzable for the aerodigestive reflex characteristics in the $\mathrm{S}-\mathrm{CHD}, \mathrm{CHD}$, and control groups, respectively. The cumulative response rate of pharyngo-upper esophageal sphincter contractile response (PUCR) and pharyngeal reflexive swallow (PRS) was $81 \%$ (54 out of 67) in S-CHD vs. 89\% (50 out of 56) CHD vs. $72 \%$ (53 out of 74$)$ in control $(P=0.047)$. However,

Table 1. Demographic and outcome characteristics

\begin{tabular}{lccc}
\hline Characteristics & $\mathrm{S}-\mathrm{CHD}(n=12)$ & $\mathrm{CHD}(n=10)$ & $\begin{array}{c}\text { Controls } \\
(n=12)\end{array}$ \\
\hline Birth GA, wk & $32.6 \pm 1.1$ & $32.9 \pm 1.6$ & $32.8 \pm 1.6$ \\
PMA at study, wk & $46.8 \pm 1.4^{* \dagger}$ & $42.5 \pm 0.7^{*}$ & $40.6 \pm 0.7^{\dagger}$ \\
Birth weight, kg & $1.64 \pm 0.2$ & $2 \pm 0.4$ & $2.3 \pm 0.4$ \\
Weight at study, kg & $3.44 \pm 0.75$ & $3.3 \pm 0.64$ & $3.86 \pm 1.06$ \\
Male, $n(\%)$ & $7(58)$ & $3(25)$ & $6(50)$ \\
\hline
\end{tabular}

Values are mean \pm SE or as stated.

CHD, congenital heart disease; PMA, postmenstrual age; S-CHD, surgical congenital heart disease.

${ }^{*} P=0.003 ;{ }^{+} P<0.001$. Other characteristics were similar in all three groups $(P>0.05)$. further analysis of immediate first responses revealed that the distribution frequency of PUCR, PRS, and none were different (Figures 1 and 2). Further analysis revealed that volume response analysis was different for PUCR (Figure 3).

\section{Impact of Flow Rates on Type of Response}

The various infusion volumes were given abruptly in all cases. The catheters are not rigid, as they are made of silicone and offer resistance. Hence, the infusion flow rates are different, but on further analysis, the infusion flow rates were similar in three groups (ANOVA, $P=0.73$ ). On further analysis, we found that the distribution of infusion flow rates were similar, when PUCR and PRS response were present (ANOVA, $P=0.49$ ). Using logistic regression, the flow rates were not found to affect the type of response (PUCR or PRS) $(P=0.49)$. On further analysis, even within the three groups, the flow rates did not affect the type of response: S-CHD $(P=0.80)$, CHD $(P=0.91)$, and control $(P=0.31)$.

\section{Pharyngeal and Upper Esophageal Sphincter Response Characteristics}

In $\mathrm{S}-\mathrm{CHD}$ vs. CHD vs. controls, respectively, resting upper esophageal sphincter (UES) pressures (12.3 \pm 1.9 vs. $8.7 \pm 2.0$ vs. $13.5 \pm 2.2 \mathrm{~mm} \mathrm{Hg}$, respectively) and response latency of PUCR and PRS ( $4.3 \pm 0.6$ vs. $4.8 \pm 0.6$ vs. $5.0 \pm 0.6 \mathrm{~s})$ were simi$\operatorname{lar}(P>0.05$; Figure 4$)$.

\section{Esophageal Body Peristaltic Response}

Response latency to esophageal peristalsis was similar in all three groups (Figure 4). On the other hand, S-CHD infants showed prolonged duration of esophageal peristalsis compared with controls (Figure 4). For the esophageal peristaltic responses, 49 out of 54 (90.7\%) in S-CHD, 46 out of 50 (92\%) in $\mathrm{CHD}$, and 51 out of $53(96 \%)$ in controls were completely propagated. The remainder of esophageal peristaltic responses

Table 2. Characteristics of S-CHD infants

\begin{tabular}{|c|c|c|c|c|c|}
\hline Patient ID & Cardiac defect & Cardiac surgery & $\mathrm{GA}(w \mathrm{k})$ & $\begin{array}{l}\text { PMA at } \\
\text { surgery (wk) }\end{array}$ & $\begin{array}{l}\text { PMA at } \\
\text { study (wk) }\end{array}$ \\
\hline 1 & Critical aortic valve stenosis & Damus-Kaye-Stansel, Blalock-Taussig shunt & 29 & 39.9 & 48.9 \\
\hline 2 & Hypoplastic right heart syndrome & Right modified Blalock-Taussig shunt & 34 & 43.6 & 51.1 \\
\hline 3 & Coarctation of aorta, VSD & Aortic arch augmentation, VSD closure & 33 & 39.4 & 42.1 \\
\hline 4 & Interrupted aortic arch & Aortic arch repair and augmentation & 29 & 29.3 & 45.6 \\
\hline 5 & Hyoplastic left heart, VSD, ASD, PDA & Coarctation repair, pulmonary valvuloplasty & 39 & 41.4 & 47.7 \\
\hline 6 & Dilated cardiomyopathy & Heart transplant & 40 & 47.1 & 52.7 \\
\hline 7 & Transposition of Great arteries & Great arteries switch & 27.7 & 40.4 & 48.1 \\
\hline 8 & ASD, VSD, PDA & ASD \& VSD patch, PDA ligation & 33 & 44.3 & 49 \\
\hline 9 & Coarctation of Aorta, PDA & Coarctation repair, PDA ligation & 31 & 37.0 & 40.0 \\
\hline 10 & ASD & ASD patch & 31 & 47.4 & 49 \\
\hline \multirow[t]{2}{*}{11} & Complete heart block & Cardiac pacemaker implantation & 32 & 32.1 & 41.9 \\
\hline & Tetralogy of Fallot & & & & \\
\hline 12 & Tetralogy of Fallot & $\begin{array}{l}\text { Right ventricle outflow tract patch repair, } \\
\text { VSD patch repair, and a ASD and PDA closed }\end{array}$ & 33 & 42 & 45.7 \\
\hline
\end{tabular}

ASD, atrial septal defect; GA, gestational age; PDA, patent ductus arteriosus; PMA, postmenstrual age; S-CHD, surgical congenital heart disease; VSD, ventricular septal defect. 
failed or incompletely propagated. There was no retrograde esophageal peristaltic propagation seen in any of the groups. Among the esophageal peristalsis, which were completely propagated, $83.7 \%$ from S-CHD, 78.2\% from CHD, and 90.1\% from controls propagated in anterograde manner, and remainder propagated in synchronous manner $(P=0.27)$.

\section{Lower Esophageal Sphincter Relaxation Characteristics}

Resting lower esophageal sphincter (LES) pressures were similar in S-CHD vs. CHD vs. controls $(17.1 \pm 1.8$ vs. $18.8 \pm 1.9$ vs. $19.3 \pm 2.1 \mathrm{~mm} \mathrm{Hg}$, respectively). LES relaxation frequency and type, LES nadir pressure, latency to LES relaxation, LES relaxation duration, and LES nadir duration were all similar $(P>0.05$; Table 4$)$.

Table 3. Characteristics of CHD infants

\begin{tabular}{llcc}
\hline \multirow{2}{*}{ Patient ID } & \multicolumn{1}{c}{ Cardiac defect } & GA in weeks & $\begin{array}{c}\text { PMA study } \\
\text { in weeks }\end{array}$ \\
\hline 1 & VSD, ASD & 35 & 45.7 \\
2 & VSD & 27 & 39.9 \\
3 & VSD & 36 & 45.0 \\
4 & VSD & 39 & 41.3 \\
5 & Pulmonary valve stenosis, ASD & 25 & 38.5 \\
6 & VSD & 36 & 42.6 \\
7 & Complete atrioventricular (AV) & 38 & 45.3 \\
& canal defect & & \\
9 & ASD & 35 & 40.9 \\
10 & Pulmonary valve stenosis & 30 & 41.1 \\
& L-Transposition of great & 28 & 40.71 \\
\hline
\end{tabular}

ASD, atrial septal defect; GA, gestational age; PMA, postmenstrual age; VSD, ventricular septal defect.

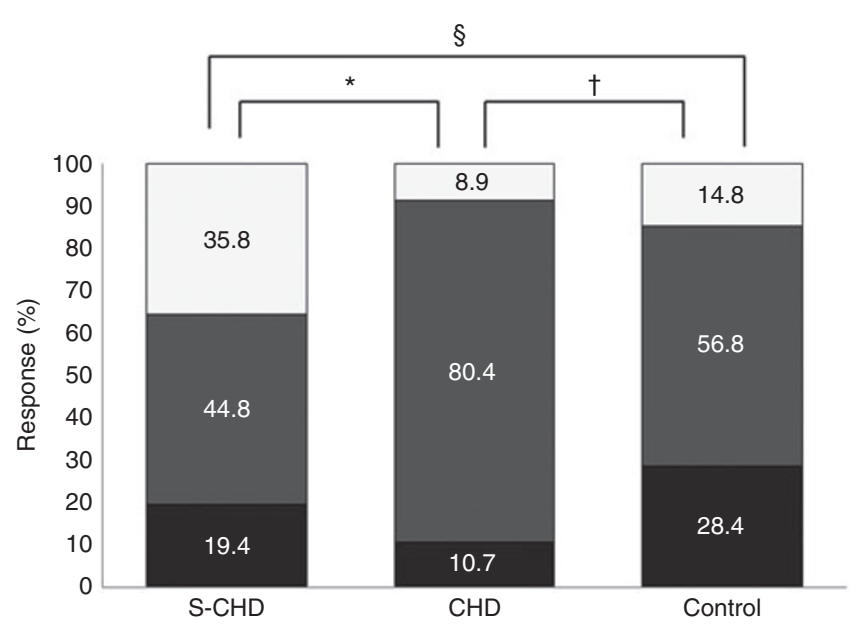

Figure 1. Frequency distribution of PUCR and PRS as primary response to pharyngeal provocation. $\square$, PUCR; $\square$, PRS; $\square$, no response. ${ }^{*} P<0.001$, ${ }^{+} P=0.02,{ }^{{ }} P<0.001$. PUCR occurred more frequently in S-CHD vs. CHD $(P=0.02)$ and controls $(P<0.001)$. NR, no response; PRS, pharyngeal reflexive swallows; PUCR, pharyngo-upper esophageal sphincter contractile response.

\section{DISCUSSION}

Oropharyngeal dysphagia and feeding difficulties are common in infants with congenital heart disease, and the mechanisms remain unclear. This is the first study that attempted to clarify the effects of pharyngeal provocation on the upper and LES sphincter functions in addition to peristaltic reflexes, in a prototype of infants with congenital heart disease. In this study, we demonstrated significant pharyngoesophageal dysmotility mechanisms in the infants with congenital heart disease, especially among those underwent cardiac surgery. Importantly, peristaltic reflexes and UES contractile responses were aberrant, while LES relaxation responses were preserved. Also, our data suggest increased efferent cholinergic excitatory activity as the basis for: (i) the increased frequency of pharyngo-UES contractile responses and (ii) decreased cholinergic inhibitory activity resulting in prolonged esophageal body response in congenital heart disease infants who underwent cardiac surgery. However, the response latencies of studied reflexes were similar in these infants compared with controls, signifying normal reaction to evoke a motor response. Interestingly, we observed that the cholinergic inhibitory responses at the LES level are unaffected, thus implying that nitric oxide or vasoactive intestinal polypeptide-mediated LES relaxation is intact.

S-CHD infants show longer duration of esophageal peristalsis and longer duration from stimulus onset to terminal esophageal response compared with controls. This suggests that cholinergic excitatory activity at the level of esophageal smooth muscle is prolonged implicating slower clearance, which is further supported by delay in restoring esophageal quiescence. Alternatively, these findings also imply prolonged afferent sensitivity resulting in prolonged efferent motor outputs at the esophageal level.

Aero-digestive reflex responses are important in the clearance of aerodigestive tract during deglutition in addition to maintaining airway safety. Using a novel experimental design and provocative interrogation of pharyngoesophageal motility reflexes, we determined the sensorimotor characteristics. Prevalence of feeding difficulties in infants with $\mathrm{CHD}$ is high, especially in those undergoing cardiac surgeries with incidences varying from 22 to $50 \%$ (5-7). It is likely that the effects of associated pathobiologic factors, such as inflammation, surgical and visceral trauma, circulatory changes, chronic ventilation, or airway disease, may have altered sensorimotor characteristics of the studied reflexes $(5,6,11,16-18)$. Inflammation modifies the myoelectric and peristaltic functions of viscera $(19,20)$. Also, it is well known that various neural pathways are affected due to thoracic surgeries, and various factors, such as intubations or hypothermia, have been attributed $(21,22)$. These factors potentially alter pharyngoesophageal reflexes responsible for pharyngoesophageal clearance leading to aerodigestive problems (23).

The selection of subjects in the current study is by natural referral and may represent the severe forms of dysphagia. Nevertheless, we made pilot observations such that there are differences between the surgical CHD and nonsurgical CHD. 


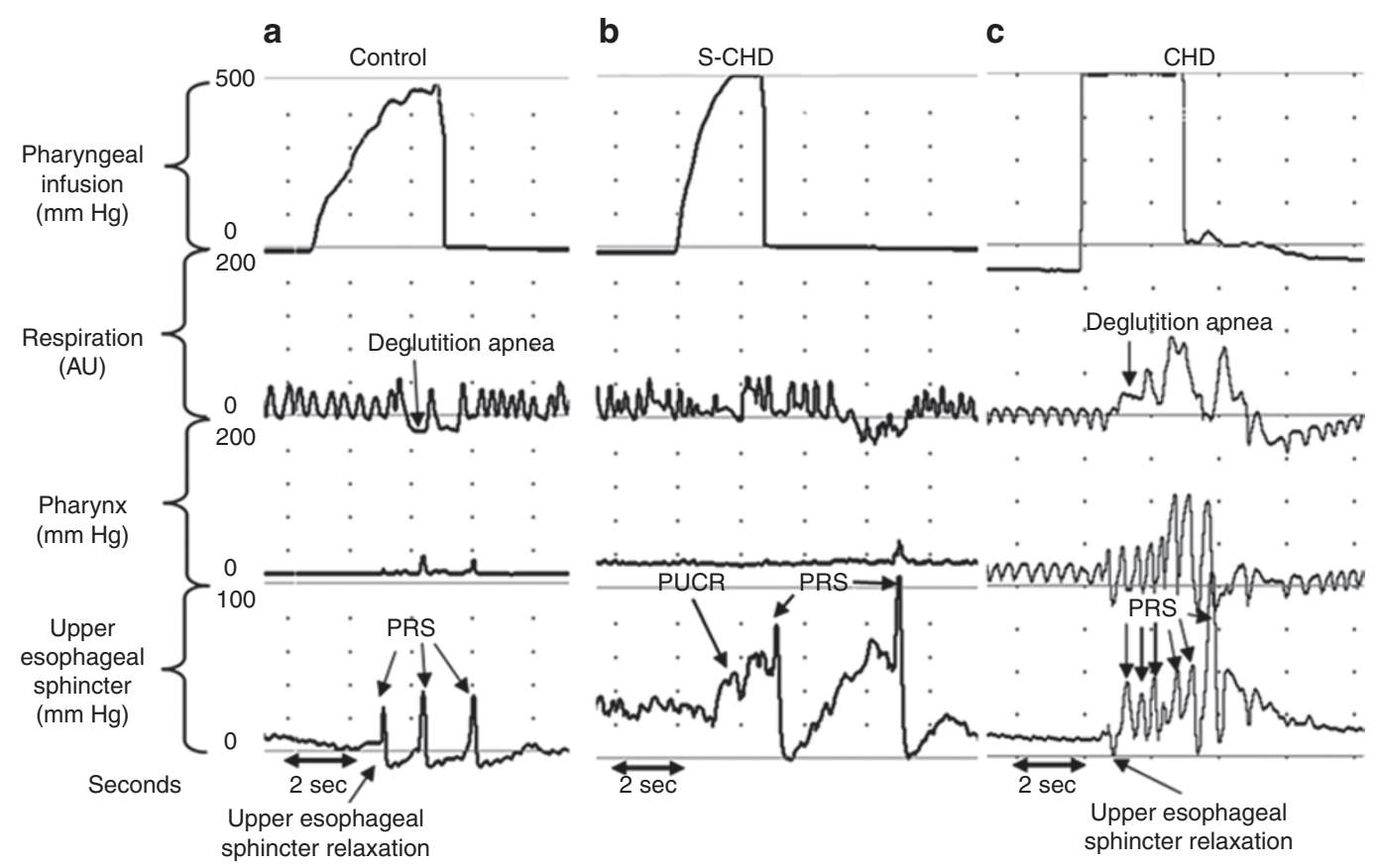

Figure 2. Pharyngoesophageal manometry. Effect on UES of $0.3 \mathrm{ml}$ pharyngeal water infusion in (a) control, (b) S-CHD, and (c) CHD. In response to pharyngeal water infusion, UES contraction is seen in S-CHD vs. UES relaxation in control and CHD. CHD, congenital heart disease infants; S-CHD, surgical congenital heart disease; UES, upper esophageal sphincter.

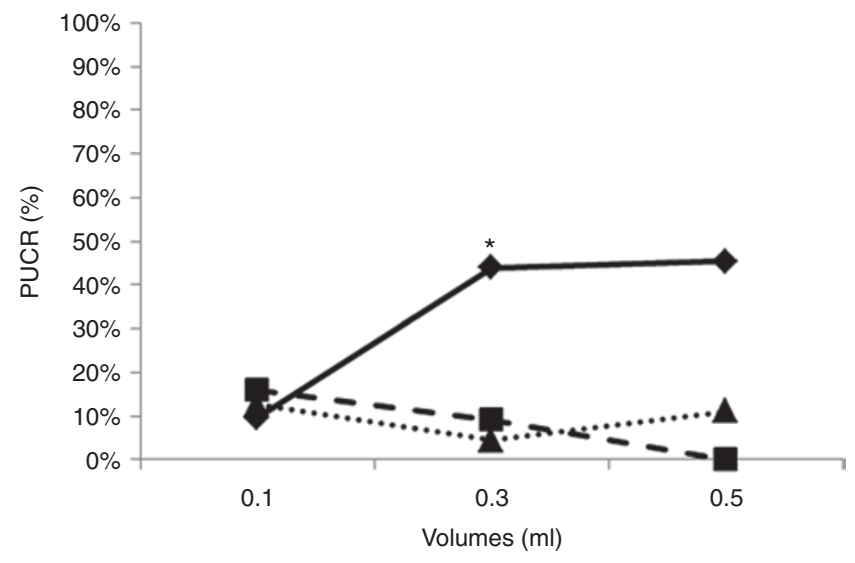

Figure 3. Distribution of PUCR at different stimulus volumes. control; $\cdot--1-$, CHD; $\longrightarrow$ S-CHD. ${ }^{*} P=0.002$ vs. CHD, $P=0.01$ vs. control. Overall, stimulus-response relationships were evident with increased recruitment of PUCR frequency with increasing volumes (S-CHD vs. CHD, $P=0.06$, ANOVA and S-CHD vs. control, $P=0.06$, ANOVA). Specifically, PUCR frequency is similar in all three groups at $0.1 \mathrm{ml}$. In contrast, at $0.3 \mathrm{ml}$ stimulus, PUCR frequency is significantly higher in S-CHD vs. CHD $(P=$ $0.002)$ and S-CHD vs. controls $(P=0.01)$. However, with $0.5 \mathrm{ml}$ infusions, increased recruitment of PUCR frequency were noted though not statistically significant ( $\mathrm{S}-\mathrm{CHD}$ vs. CHD, $P=0.16$ and $\mathrm{S}-\mathrm{CHD}$ vs. controls, $P=0.06$ ); this may be due to limited number of $0.5 \mathrm{ml}$ infusions administered. CHD, congenital heart disease infants; PUCR, pharyngo-upper esophageal sphincter contractile response; S-CHD, surgical congenital heart disease.

Indeed, the severity of CHD may vary between subjects, and both of these groups are representative of heterogeneity with varying severity, surgical approaches, and variable duration of postoperative care. Further studies are needed to clarify differences in mechanisms in specific congenital heart defects before and after major interventions.
The implications of this study are several. It is well recognized that infants with differing congenital heart conditions have difficulty in transitioning from tube to oral feeding. This is a first attempt to identify potential causes for such issues. It is commonly speculated that surgical manipulation and perioperative course in the congenital heart disease infants interferes with central and enteric nervous system communication with potential for significant aerodigestive maladaptation affecting safety and function. Our study supports this concept. Pharyngo-UES contractile reflex is the frequent response to pharyngeal infusion in adults in contrast to neonates in whom PRS is common response $(24,25)$. Though delineation of exact pathways is difficult in human subjects, earlier study in cats has shown that glossopharyngeal nerve acts as afferent while vagal nerve acts as efferent for this reflex (26). In our study, we have shown that response latency of pharynx, UES, and esophagus being similar in all three groups points to relative sparing of afferent pathways. At the same time, prolonged esophageal peristaltic motor activity points to the involvement of vagal efferent motor neural pathways. Further studies will provide a better understanding of the etiopathological mechanisms and open doors for the development of preventive and interventional strategies to assist infants with congenital heart conditions become more successful at oral feeding. This would be an important area of clinical research. Minimally invasive surgery and lesser manipulation of esophagus during the surgery may reduce local injury and/or inflammation around the neural pathways, thus potentially helping in prevention of dysphagia. Early oro-motor therapy may help in redevelopment of neuronal pathways to UES thereby ameliorating dysphagia. Development of mechanisms of neuroplasticity, 


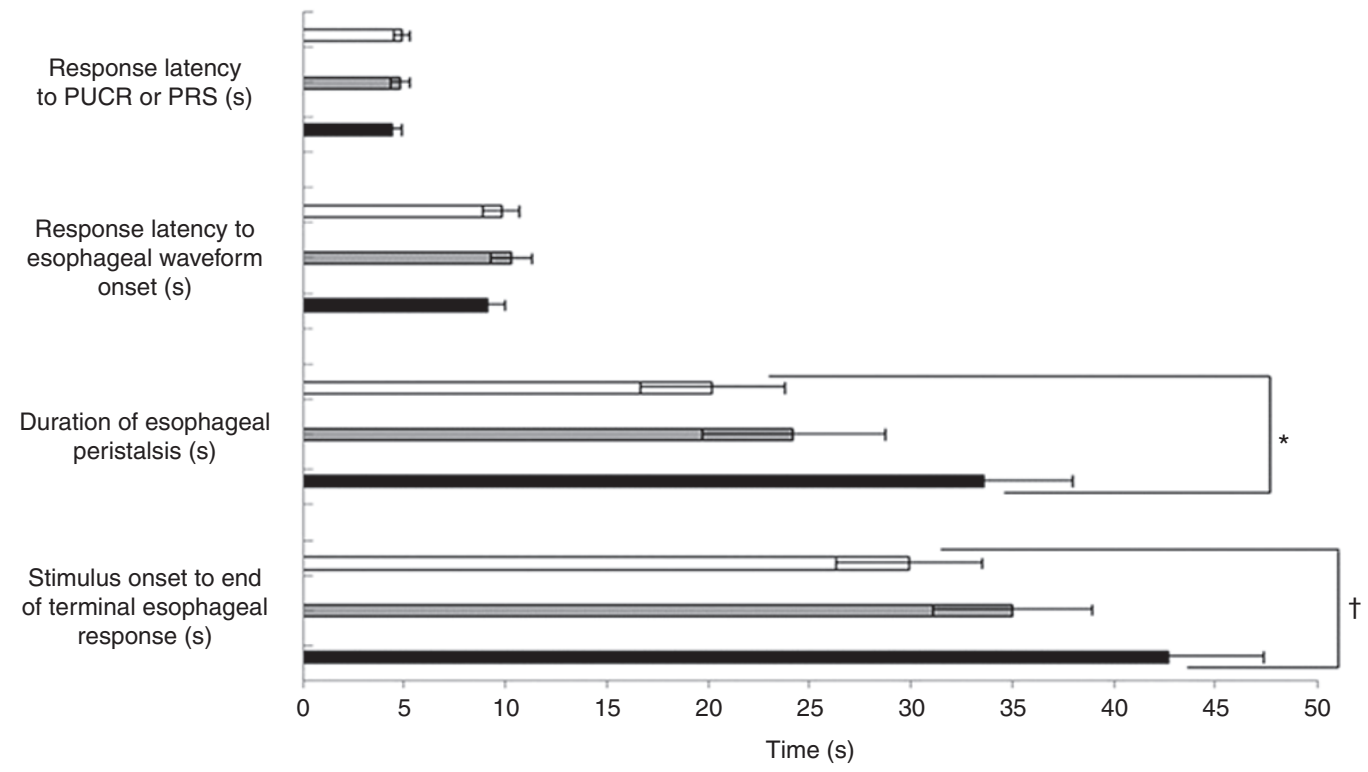

Figure 4. Evaluation of relationship between stimulus and peristaltic response. $\square$, control; $\square, \mathrm{CHD} \square, \mathrm{Q}$-CHD. ${ }^{*} P=0.04,{ }^{+} P=0.01$. Response latency was similar in all thee groups for PUCR or PRS and onset of esophageal waveform. However, duration of esophageal peristalsis and duration from stimulus onset to terminal esophageal waveform were significantly longer in S-CHD vs. control $(P<0.05)$. PRS, pharyngeal reflexive swallows; PUCR, pharyngoupper esophageal sphincter contractile response; S-CHD, surgical congenital heart disease.

Table 4. Characteristics of LES relaxation reflex

\begin{tabular}{|c|c|c|c|}
\hline Characteristics & $\mathrm{S}-\mathrm{CHD}$ & CHD & Controls \\
\hline LES relaxation, frequency (\%) & 79 & 82 & 72 \\
\hline $\begin{array}{l}\text { Response latency to LES } \\
\text { relaxation (s) }\end{array}$ & $4.6 \pm 0.6$ & $5.1 \pm 0.6$ & $5.6 \pm 0.7$ \\
\hline $\begin{array}{l}\text { Duration of active LES } \\
\text { relaxation }(s)\end{array}$ & $2.3 \pm 0.5$ & $3.0 \pm 0.6$ & $2.9 \pm 0.5$ \\
\hline $\begin{array}{l}\text { Duration of complete LES } \\
\text { relaxation nadir (s) }\end{array}$ & $22.4 \pm 4.9$ & $15.0 \pm 5.3$ & $13.0 \pm 2.1$ \\
\hline $\begin{array}{l}\text { Magnitude of LES relaxation, } \\
\text { nadir pressure }(\mathrm{mm} \mathrm{Hg})\end{array}$ & $-1.5 \pm 0.8$ & $-0.8 \pm 0.9$ & $-1.4 \pm 1.0$ \\
\hline
\end{tabular}

Values are least-square mean \pm SE or as stated otherwise. LES relaxation characteristics were similar in all three groups $(P>0.05)$.

CHD, congenital heart disease; LES, lower esophageal sphincter; S-CHD, surgical congenital heart disease.

sucking-swallowing-peristalsis rhythms, and appropriate oral sensory processing may help in regeneration and restoration of neuromotor functions.

This study has limitation in that the patient population was heterogeneous with a variety of congenital heart diseases and underwent different cardiac surgeries. In addition, temporal changes in pharyngoesophageal motility due to maturational changes can happen with time, and we need further studies to elucidate the maturational or modifiable changes. Limited specific CHD subsets did not permit us to perform subgroup analysis. In patients, who did not respond to lower volume of infusions, higher volume infusions were not given in some cases due to concerns for patient's safety. In such cases, threshold volume may be generally greater thus supporting extreme hyposensitivity. Generally, we see the responses to $0.3 \mathrm{ml}$ in $90 \%$ of infusions (18).

Feeding difficulties in children at risk for undergoing cardiac surgeries further lead to inadequate nutritional intake, resulting in poor growth. Also, a strong association exists between decrease in weight for age and mortality during the first year of life and during the first months following surgery for correction of congenital cardiac disease (27). The neuromotor dysfunction and immaturity of cerebral development that exists in infants with congenital heart disease also places them at risk for aerodigestive problems $(14,15)$. With this in mind, multiple studies, surgeries, and medications may put them at additional risk given the lack of proven therapies for esophageal or aerodigestive malfunctions. Procedures, such as gastrostomy or fundoplication, although frequently performed, do not account for underlying dysmotility. Given the fact that LES characteristics were normal in infants with congenital heart disease, fundoplication should be performed with caution since increasing LES tone may further lead to worsening of dysphagia in these infants as well as increasing chances of anterograde aspiration in dysphagic infants. In this study, the dysmotility mechanisms were indicative of proximal aerodigestive maladaptation. Furthermore, infants with CHD who got gastric fundoplication have been found to be associated with significantly increased interstage mortality than infants with CHD who did not get this procedure (28).

In summary, based on the current study, UES hyperactivity may be an early therapeutic target. This is the first study to highlight these findings. Differences as well as longitudinal changes in UES and LES functions in infants with congenital heart diseases will need further investigations.

\section{METHODS}

\section{Participants}

Infants with congenital heart disease $(n=22 ; 10$ males) born at gestational age (GA) range 25-40 wk were evaluated between 38 and $52 \mathrm{wk}$ postmenstrual age (PMA) for dysphagia at the neonatal and infantfeeding disorders program, at the Nationwide Children's Hospital, 
Columbus, Ohio. Among these, 12 infants underwent cardiac surgeries for severe congenital heart disease for various reasons, and 10 infants did not undergo cardiac surgery. To compare data, 12 healthy control infants who had independent oral feeding skills ( 6 males; born at GA range $24-40 \mathrm{wk}$ ) were studied at PMA range $37-45 \mathrm{wk}$. These controls were part of other ongoing research studies and were feeding and thriving appropriately during the hospital course and did not have any genetic or birth defects. All subjects were evaluated by us and the primary neonatologist and were deemed appropriate for study procedures. The study observations reported are from retrospectively collected pharyngoesophageal manometry data recordings, and the Institutional Review Board approvals were obtained at the Nationwide Children's Hospital Research Institute, Columbus, Ohio. Written, informed consents were obtained from parents before study, and Health Insurance Portability and Accountability Act compliance was followed.

\section{Manometry Methods}

The use of esophageal manometry methods and multimodal provocation techniques in neonates was described by our group $(25,29-$ 31). Briefly, the catheter assembly (Dentsleeve International; Mui Scientific, Mississauga, Ontario, Canada) was connected to the pneumohydraulic micromanometric water perfusion system via the resistors, pressure transducers, and amplifiers (solar modules, Solar 2; MMS Medical Instruments, Dover, NH). The esophageal manometry catheter assembly with dual sleeves (recording from UES and LES) and four side ports recording from pharynx, proximal, middle, and distal esophageal loci, and a terminal gastric recording port was used. The catheter also includes a dedicated infusion channel to provide esophageal stimulus. The water perfusion rate was $0.02 \mathrm{ml} / \mathrm{min}$ per port for esophageal ports, $0.01 \mathrm{ml} / \mathrm{min}$ per port for the pharyngeal port, and $0.04 \mathrm{ml} / \mathrm{min}$ per port for the sleeves. The catheter was passed nasally in the unsedated supine lying neonate, and all studies were done in the same manner, with the transducers at the level of the subject's esophagus (midaxillary line). Vital signs were monitored for safety during the manometry study.

\section{Manometric Experimental Protocol}

Continuous data acquisition and analysis were performed based on manometric waveform characteristics $(25,29-31)$. Pharyngeal provocations with sterile water were performed to test the effects of osmosensitive stimulation. During catheter placement and pull through, the UES and LES sleeves were positioned such that they straddled the UES and LES high-pressure zones, respectively, and were identified by the presence of a consistent increase in pressure of $5.0 \mathrm{~mm}$ $\mathrm{Hg}$ above the baseline for at least $15 \mathrm{~s}$, in addition to the changes in pressure with respiration. After neonates were allowed to adapt for about $15 \mathrm{~min}$, we evaluated responses to pharyngeal provocation. In our study, we gave graded infusion volumes of water $(0.1,0.3$, and $0.5 \mathrm{ml}$ ) into the pharynx with each dose given thrice. However, in nonresponders' higher volume infusions were not given in some cases due concerns for patient's safety.

\section{Manometry Data Analysis}

The signature manometric waveforms related to UES, LES, and esophageal reflex characteristics were analyzed as defined before $(25,29-32)$. Briefly, PRS was defined as a deglutition response within $5 \mathrm{~s}$ of pharyngeal infusion, which begins with the onset of the pharyngeal waveform associated with UES relaxation, propagates into the proximal, middle, and distal esophageal segments, and is accompanied by LES relaxation. On the other hand, PUCR was defined as an increase in UES pressure $>4 \mathrm{~mm} \mathrm{Hg}$ within $5 \mathrm{~s}$ of pharyngeal infusion (25). Response latency was defined as the duration from the onset of pharyngeal stimulus to the onset of PRS or PUCR or peristaltic reflex. As referenced before, resting UES pressure and LES pressure were measured (16-20). Resting pressures were measured as an average of five pressure measurements at the end of expiration observed before the onset of stimulus. Response latency to PUCR was defined as the time taken from the onset of stimulus for an increase in UES pressure of at least $4 \mathrm{~mm} \mathrm{Hg}$ above baseline. Maximum UES contractile pressure was also measured to ascertain the UES contractile reflex magnitude as a difference in onset and peak UES contractile pressures. Specific to the present study, LES resting pressure and relaxation were evaluated as follows:
1. LES resting pressure was evaluated before the onset of the infusion, as a mean of five observations of LES pressure in relation to gastric pressure at end expiration.

2. LES response latency is duration from the onset of pharyngeal infusion to onset of LES relaxation, i.e., when LES pressure dropped at least $5 \mathrm{~mm} \mathrm{Hg}$ below LES resting pressure.

3. Duration of active LES relaxation was defined as duration from the onset of LES relaxation to the start of LES nadir.

4. Nadir was defined as the lowest pressure point reached by the LES, and nadir pressure was the lowest pressure taken during nadir duration.

5. Nadir duration was considered as the period during which LES pressure dropped to $5.0 \mathrm{~mm} \mathrm{Hg}$ or less and up to the point LES pressure recovered to $5.0 \mathrm{~mm} \mathrm{Hg}$.

All pressures were taken at the end of expiration and in relation to gastric pressure (32).

\section{Statistical Methods}

Subject characteristics, manometric measurements, and outcome variables were compared among the S-CHD, CHD, and control groups. Multinomial mixed models and linear mixed models with compound symmetry matrix were used to analyze the repeated measures data. Statistical tests were adjusted for multiple comparisons using the Tukey-Kramer method. These models were fit using PROC GENMOD for categorical responses and PROC MIXED for continuous responses in SAS (SAS v.9.2; SAS Institute, Cary, NC). To evaluate the effect of graded volume on the recruitment of reflexes, we used ANOVA and $\chi^{2}$ tests and compared among the groups (Figure 3 ). Descriptive data are reported as least-square means \pm SE, percentages, or as range unless stated otherwise.

\section{ACKNOWLEDGMENTS}

We are grateful to Eva Gao for statistical support and Rebecca Moore for nursing assistance.

\section{STATEMENT OF FINANCIAL SUPPORT}

S.J's efforts were supported by grant R01(DK) 068158 from the National Institutes of Health (Bethesda, MD).

\section{REFERENCES}

1. Hoffman JI, Kaplan S. The incidence of congenital heart disease. J Am Coll Cardiol 2002;39:1890-900.

2. Varan B, Tokel K, Yilmaz G. Malnutrition and growth failure in cyanotic and acyanotic congenital heart disease with and without pulmonary hypertension. Arch Dis Child 1999;81:49-52.

3. Kastner TA, Committee on Children with Disabilities. Managed care and children with special health care needs. Pediatrics 2004;114: 1693-8.

4. American Academy of Pediatrics Committee on Fetus and Newborn. Hospital discharge of the high-risk neonate. Pediatrics 2008;122:1119-26.

5. Maurer I, Latal B, Geissmann H, Knirsch W, Bauersfeld U, Balmer C. Prevalence and predictors of later feeding disorders in children who underwent neonatal cardiac surgery for congenital heart disease. Cardiol Young 2011;21:303-9.

6. Skinner ML, Halstead LA, Rubinstein CS, Atz AM, Andrews D, Bradley SM. Laryngopharyngeal dysfunction after the Norwood procedure. J Thorac Cardiovasc Surg 2005;130:1293-301.

7. Yi SH, Kim SJ, Huh J, Jun TG, Cheon HJ, Kwon JY. Dysphagia in infants after open heart procedures. Am J Phys Med Rehabil 2013;92:496-503.

8. Kelleher DK, Laussen P, Teixeira-Pinto A, Duggan C. Growth and correlates of nutritional status among infants with hypoplastic left heart syndrome (HLHS) after stage 1 Norwood procedure. Nutrition 2006;22:23744.

9. Jadcherla SR, Vijayapal AS, Leuthner S. Feeding abilities in neonates with congenital heart disease: a retrospective study. J Perinatol 2009;29: $112-8$.

10. Averin K, Uzark K, Beekman RH 3rd, Willging JP, Pratt J, Manning PB. Postoperative assessment of laryngopharyngeal dysfunction in neonates after Norwood operation. Ann Thorac Surg 2012;94:1257-61. 
11. Einarson KD, Arthur HM. Predictors of oral feeding difficulty in cardiac surgical infants. Pediatr Nurs 2003;29:315-9.

12. Imms C. Feeding the infant with congenital heart disease: an occupational performance challenge. Am J Occup Ther 2001;55:277-84.

13. Kogon BE, Ramaswamy V, Todd K, et al. Feeding difficulty in newborns following congenital heart surgery. Congenit Heart Dis 2007;2:332-7.

14. Davis D, Davis S, Cotman K, et al. Feeding difficulties and growth delay in children with hypoplastic left heart syndrome versus $d$-transposition of the great arteries. Pediatr Cardiol 2008;29:328-33.

15. Licht DJ, Shera DM, Clancy RR, et al. Brain maturation is delayed in infants with complex congenital heart defects. J Thorac Cardiovasc Surg 2009;137:529-36.

16. Ohri SK, Somasundaram S, Koak Y, et al. The effect of intestinal hypoperfusion on intestinal absorption and permeability during cardiopulmonary bypass. Gastroenterology 1994;106:318-23.

17. Sachdeva R, Hussain E, Moss MM, et al. Vocal cord dysfunction and feeding difficulties after pediatric cardiovascular surgery. J Pediatr 2007;151:312-5, 315.e1-2.

18. Tárnok A, Schneider P. Pediatric cardiac surgery with cardiopulmonary bypass: pathways contributing to transient systemic immune suppression. Shock 2001;16:Suppl 1:24-32.

19. Jadcherla SR. Inflammation inhibits muscarinic signaling in in vivo canine colonic circular smooth muscle cells. Pediatr Res 2002;52:756-62.

20. Shafik A, El-Sibai O, Shafik I, Shafik A. Electroesophagogram in gastroesophageal reflux disease with a new theory on the pathogenesis of its electric changes. BMC Surg 2004;4:13.

21. Lederman RJ, Breuer AC, Hanson MR, et al. Peripheral nervous system complications of coronary artery bypass graft surgery. Ann Neurol 1982;12:297-301.

22. Shafei H, el-Kholy A, Azmy S, Ebrahim M, al-Ebrahim K. Vocal cord dysfunction after cardiac surgery: an overlooked complication. Eur J Cardiothorac Surg 1997;11:564-6.
23. Jadcherla S, Parks V, Chan C, Pizzuti M, Peng J. Significance of peristaltic reflexes (PR) on esophageal clearance in human neonates: assessed by novel abrupt mid esophageal provocation during concurrent manometry and impedance. Neurogastroent Motil 2011;23:5-6.

24. Shaker R, Ren J, Xie P, Lang IM, Bardan E, Sui Z. Characterization of the pharyngo-UES contractile reflex in humans. Am J Physiol 1997;273(4 Pt 1):G854-8.

25. Jadcherla SR, Gupta A, Stoner E, Fernandez S, Shaker R. Pharyngeal swallowing: defining pharyngeal and upper esophageal sphincter relationships in human neonates. J Pediatr 2007;151:597-603.

26. Medda BK, Lang IM, Layman R, Hogan WJ, Dodds WJ, Shaker R. Characterization and quantification of a pharyngo-UES contractile reflex in cats. Am J Physiol 1994;267(6 Pt 1):G972-83.

27. Eskedal LT, Hagemo PS, Seem E, et al. Impaired weight gain predicts risk of late death after surgery for congenital heart defects. Arch Dis Child 2008;93:495-501.

28. Hebson CL, Oster ME, Kirshbom PM, Clabby ML, Wulkan ML, Simsic JM. Association of feeding modality with interstage mortality after single-ventricle palliation. J Thorac Cardiovasc Surg 2012;144:173-7.

29. Jadcherla SR, Duong HQ, Hoffmann RG, Shaker R. Esophageal body and upper esophageal sphincter motor responses to esophageal provocation during maturation in preterm newborns. J Pediatr 2003;143:31-8.

30. Jadcherla SR, Duong HQ, Hofmann C, Hoffmann R, Shaker R. Characteristics of upper oesophageal sphincter and oesophageal body during maturation in healthy human neonates compared with adults. Neurogastroenterol Motil 2005;17:663-70.

31. Jadcherla SR, Hoffmann RG, Shaker R. Effect of maturation of the magnitude of mechanosensitive and chemosensitive reflexes in the premature human esophagus. J Pediatr 2006;149:77-82.

32. Pena EM, Parks VN, Peng J, et al. Lower esophageal sphincter relaxation reflex kinetics: effects of peristaltic reflexes and maturation in human premature neonates. Am J Physiol Gastrointest Liver Physiol 2010;299:G1386-95. 